\title{
STEM Storytellers: Improving the Oral Communication Skills of STEM Graduate Students
}

\author{
Dr. Shannon D. Willoughby, Montana State University \\ Dr. Brock J. LaMeres, Montana Engineering Education Research Center
}

Dr. Brock J. LaMeres is the Director of the Montana Engineering Education Research Center (MEERC) and an Associate Professor in the Department of Electrical \& Computer Engineering at Montana State University. LaMeres teaches and conducts research in the area of computer engineering. LaMeres is currently studying the effectiveness of online delivery of engineering content with emphasis on how the material can be modified to provide a personalized learning experience. LaMeres is also researching strategies to improve student engagement and how they can be used to improve diversity within engineering. LaMeres received his Ph.D. from the University of Colorado, Boulder. He has published over 80 manuscripts and 2 textbooks in the area of digital systems and engineering education. LaMeres has also been granted 13 US patents in the area of digital signal propagation. LaMeres is a member of ASEE, a Senior Member of IEEE, and a registered Professional Engineer in the States of Montana and Colorado. Prior to joining the MSU faculty, LaMeres worked as an R\&D engineer for Agilent Technologies in Colorado Springs, CO where he designed electronic test equipment.

\section{Dr. Bryce E. Hughes, Montana State University}

Bryce E. Hughes is an Assistant Professor in Adult and Higher Education at Montana State University, and holds a Ph.D. in Higher Education and Organizational Change from the University of California, Los Angeles, as well as an M.A. in Student Development Administration from Seattle University and a B.S. in General Engineering from Gonzaga University. His research interests include teaching and learning in engineering, STEM education policy, and diversity and equity in STEM.

\section{Chris Organ}

\section{Dr. Jennifer L. Green, Montana State University}

Dr. Green is an assistant professor of Statistics. Her research focuses on the development of statistical methodology to characterize the impact of professional development and educational programs on teacher effectiveness and student learning, and she collaborates with others in the mathematical and educational sciences to create innovative approaches for teacher development in grades K-12 and in higher education.

\section{Leila Belle Sterman, Montana State University} Kent Davis 


\title{
STEM Storytellers: Improving the Oral Communication Skills of STEM Graduate Students
}

\begin{abstract}
Members of the STEM workforce are notorious for lacking the ability to describe their work to people outside of their narrow fields. This primarily results from a lack of training in oral communication that focuses on how to communicate with the public. Graduate students do not receive extensive opportunities to practice the communication skills crucial for effective professionals. Most communication experience in graduate school comes in the form of presenting at technical conferences or presenting their work to their peers. The resulting inability to communicate effectively, and communicate to a wider audience, contributes to the void in scientific engagement of our citizens. As a long-term consequence, our broader society does not understand the importance of STEM and in turn, does not strongly support nor champion STEM-related policies. To meet the grand challenges that face our population, we need a STEM workforce with exceptional communication skills, as well as a society that understands and supports large scale initiatives to spur STEM innovation and bolster STEM education. This paper presents a novel oral communication curriculum that is being developed and tested at Montana State University (MSU). The program, called the "STEM Storytellers Program”, uses a transformative approach to training graduate students that pulls knowledge from the journalism and performing arts community. Our program has three specific components: (1) creating jargon-less podcasts; (2) receiving training from an improvisational actor on stage presence; and (3) presenting at "curiosity cafes" to audiences from the general public. This paper will present the design of the curriculum including the overarching theoretical framework, programmatic issues, and recruiting. This paper will be of interest to faculty that wish to improve graduate student oral communication skills and are seeking novel programs that are being pilot tested at other universities.
\end{abstract}

\section{Introduction}

The effective communication of science to the general public is increasingly important as our society continues to advance technologically. Many scientists realize that our work must be clearly communicated to the broader public because it can directly benefit society, is frequently publicly funded, and policy decisions should be based on the facts and scientific consensus contained in the scientific literature, but there is a gap between scholarly communication and the public understanding of science. The mission of the American Association for the Advancement of Science includes the following goals: "Promote and defend the integrity of science and its use; Promote the responsible use of science in public policy; [and] Increase public engagement with science and technology" (AAAS website). These goals frequently collide with an unfortunate reality that currently exists in graduate STEM education: the minimal training students receive typically focuses only on communicating with domain experts. STEM graduate students often lack the formal communication training needed to easily share their work with the general public. Conveying research through a narrative structure with appropriate language and tone for each audience greatly assists in the understanding of science and its appeal to a broad audience, not just to experts in similar fields (Mooney, 125). Although the scientific community agrees that training in oral communication skills will benefit our future colleagues, relatively little emphasis is placed on this training, and the research in this area is lacking ("Rising Above..", 168). 
This project described in this NSF Grantees paper/poster division is funded through the NSF Research Traineeship (NRT) Program within the Innovations in Graduate Education (IGE) track. The overarching goal of this project is to develop a fellowship program for Ph.D. students that will provided multifaceted training and practice in oral communication to prepare them to effectively convey science to people with a wide variety of backgrounds.

\section{Fellowship Program Overview}

This project is in its first year of funding and is currently designing the program for the $1^{\text {st }}$ cohort that will start in August of 2018. The program is designed to be 1-year and will be run 3 times to 3 different cohorts consisting of 8 fellows in their first year of their STEM Ph.D. program. In the first semester of the program, the students will focus on voice only communication techniques through the creation of podcasts where they describe a significant technical paper in their field with the intended audience being a non-STEM citizen. The training program will initially focus on reducing technical jargon in the audio description. To this aim, we will adapt and benchmark the jargonness equation (Sharon, 538) to measure how much jargon the students are using. This equation was developed to assess the amount of jargon in a transcribed recording and provides a numerical rating of how well the description uses common words in the English language (as opposed to within the students technical area). The equation is as follows:

$$
\text { Jargonness }=\left\{\begin{array}{lr}
\log \left(\frac{\text { frequency }_{\text {scientific }}}{\text { frequency }_{\text {general }}}\right) & \left(\text { frequency }_{\text {general }}>0\right) \\
3 & \left(\text { frequency }_{\text {general }}=0\right)
\end{array}\right\}
$$

To use this equation, the students' audio recordings throughout the semester will be transcribed and evaluated. In order to prepare a transcript for use in the jargonness equation, it must first be stripped of the 9,000 most common words in spoken English (Heatley). Next, the remaining words in the transcript will be compared to two corpora (large list) of words. When creating the jargonness equation, the developers used a corpus of scientific English called the Professional English Research Consortium Corpus, which contains approximately 17 million words (Sharon, 535). For common words, the authors used the British National Corpus as the reference corpus it contains approximately 97 million words (Sharon, 535). The remaining words in a transcript are compared to both corpora and put into three frequency bins according to how often the word appears in each corpus. Bin one includes only scientific jargon, bin two only contemporary English, and a third bin contains words that are present in both corpora. These frequencies can then be put into the jargonness equation and a value can be calculated. A ratio of frequencies is used in the first equation, which is just a count of how many times that word family is found within a given corpus. In the equation, the second calculation is used when a word is contained only in bin one, i.e., the word is strictly found in the scientific corpus and not present in the contemporary English corpus. The jargonness for each word in a given transcript is calculated, then the median jargonness for an entire transcript is determined. It is the median value of jargonness that is compared to other benchmark transcripts (i.e., TED talks, Science podcats, etc) to evaluate the students' performance. The lower the number the better. 
In the second semester the students will receive training in presenting to live audiences. A rubric will be developed by an improvisational actor to evaluate the public speaking effectiveness. This will include the jargonness equation in addition to assessment of stage presence. The competencies that the rubric will rate are:

Table 1: Public Speaking Competency Rubric Core Performance Standards

\begin{tabular}{|c|c|}
\hline $\begin{array}{c}\text { Item } \\
\text { number }\end{array}$ & Competency measured \\
\hline 1 & Selects a topic appropriate to the audience and occasion \\
\hline 2 & Formulated an introduction that orients the audience to the topic and speaker \\
\hline 3 & Uses an effective organizational pattern \\
\hline 4 & Locates, synthesizes, and employs compelling supporting materials \\
\hline 5 & Develops a conclusion that reinforces the thesis and provides a psychological closure \\
\hline 6 & Demonstrates a careful choice of words \\
\hline 7 & Effectively uses a vocal expression and paralanguage to engage the audience \\
\hline 8 & Demonstrates supportive non-verbal behavior \\
\hline 9 & Successfully adapts the presentation to the audience \\
\hline
\end{tabular}

The developed rubric will be used in evaluation of the students' presentation throughout the semester to enhance their skills. The end of the semester will be a public talk to a non-STEM audience in a curiosity café setting, which is where the students will give a presentation at a coffee bar setting to the general public.

The anticipated outcome of this fellowship is that the students show continual improvement in their presentation abilities as measured through the jargonness and public speaking rubrics. Surveys will also be administered to the fellows to measure confidence and compared to scores from the rubrics to determine correlations.

\section{Next Steps}

Currently, the recruiting materials for the 2018 STEM storyteller program is under development and the public speaking rubric is under development. At the time of the 2018 ASEE Annual conference, it is anticipated that the poster for this paper will be able to present the recruiting materials, the public speaking rubric, and any lessons learned from trying to attract $1^{\text {st }}$ year Ph.D. students into this program.

\section{References}

Mooney, C., \& Kishenbaum, S. (2009). Unscientific America: How Scientific Illiteracy Threatens our Future. New York: Basic Books.

Committee on Prospering in the Global Economy of the $21^{\text {st }}$ Century. (2007). Rising Above the Gathering Storm: Energizing and Employing America for a Brighter Economic Future. The National Academies Press: Washington D. C.

Sharon AJ and Baram-Tsabari A. (2014). Measuring mumbo jumbo: A preliminary quantification of the use of jargon in science communication, Public Understanding of Science, vol. 23, no. 5, pp. 528-546, July 2014. 